\title{
Effects of ions on the characteristics of monolayer at brine/oil interfaces
}

\author{
Mohammed B. Alotaibi ${ }^{1, *}$, Dongkyu $\mathrm{Cha}^{1}$, Karam Chand $^{1}$, and Ali A. Yousef ${ }^{1}$
}

${ }^{1}$ Saudi Aramco

\begin{abstract}
The advanced waterflooding technologies through salinity and ionic content adjustment can make favorable impacts on rock wettability and oil recovery. In carbonate reservoirs, SmartWater at low ionic strength showed strong chemical interactions with carbonate minerals and oil components. As a result, several hypotheses are proposed in literature as ionic exchange, rock dissolution, surface charges and others. The applied macroscopic and microscopic technologies have certain limitations in identifying the structures at interfaces especially at monolayers. In this paper, advanced Sum Frequency Generation (SFG) spectroscopy is utilized for the first time to characterize the chemical structures of molecules at the brine/oil interfaces. Different brines recipes and model oil are tested to determine the effects of individual and combined ions on the monolayer structures. Stearic acid is also mixed with hydrocarbons to mimic the acidity condition of fluids in the reservoir. The change in the chemical structure is monitored with time at a broad wavenumber range from 1,000 to $3,800 \mathrm{~cm}-1$. Distinct spectral signatures of oil components and water ions are detected at different $\mathrm{pH}$ conditions. The SFG data is compared with the previous macroscopic wettability results to predict the components that are highly affected during waterflooding and enhanced oil recovery (EOR) processes. This study brings new insights on understanding the chemical structures at the thin monolayers of flat and curved geometric at different aqueous interfaces. The measured spectra, coupled with a wide range of laser polarization settings, and signal intensity trends are discussed in terms of composition, and structure of organic and inorganic components. For example, the intensity for SmartWater at certain wavenumber is three folds higher when compared to high salinity water. This indicates that the interactions at oil/water interfaces are enhanced at lower ionic strengths. In addition, these findings are also confirmed with similar behaviors at a higher salinity brine as connate formation brine. The novelty of this interfacial study can provide better understanding of the reaction mechanisms altering the ionic strength and salinity of injection water and its impact due to the changes in geometric interfaces. Such understanding is also crucial to optimize the chemistry of injection water and its interaction with oil components and carbonate rock, to ultimately alter wettability toward water-wet.
\end{abstract}

\section{Introduction}

Over the last decade, laboratory studies, single well chemical tracer tests and several field pilots, in clastic and carbonate reservoirs, have demonstrated that additional oil can be recovered after modifying the injection water chemistry $[1,2]$. The water salinity heavily depends on the nearest available water resources and it varies from one field to another accordingly. Therefore, there is a high contrast between the concentration of the monovalent and divalent ions as well as the dissolved ions ratios. Such variations can complicate the chemical interactions between fluids and reservoir minerals especially that certain ions comes in different forms as free and/or complexes. As a result, the ions can either directly adhere to the interfaces or form outer sphere bridges through water molecules [3].

In general, water chemistry can be reformed in different ways either by dilution or increasing and decreasing individual ions' concentration specially calcium, magnesium, sodium and sulfate. The aim of designing optimum recipes for waterflooding, as SmartWater and low salinity, is mainly to make a favorable impact on the fluids interactions and rock wettability accordingly. Diverse hypothesis causes the observed changes in wettability and oil recovery as the following: 1) adsorption of sulphate ions associated with co-adsorption of divalent cations, 2) change in the surface charges at interfaces, and 3) microscopic dissolution of anhydrites [4].

Previous research studies focused on macroscopic/microscopic techniques (coreflooding, spontaneous imbibition, contact angles, NMR, zeta potential), which cannot assist in understanding the molecular interactions and reaction mechanisms in specific at interfaces $[5,6]$. Therefore, the objective of this paper is to characterize the chemical structures of oil and brine components in situ at oil/water interfaces.

Multiple surface characterizing techniques have been applied to characterize the chemical interactions at interfaces. However, the interfacial layers in presence of oil systems are barely covered for emulsions only $[7,8]$. Most of the SFG studies are not directly related to the 
advanced waterflooding and focused more on topics related to air/water interfaces, hydrogen bonding, lubricant oil, polymers and surfactants, bitumen extraction, ionic liquids, lipids/water interfaces, and marine aerosols [9-12].

$\mathrm{Hu}$ and Chou [13] conducted SFG spectroscopy studies at bitumen/water interfaces for different $\mathrm{pH}$ and ionic strength solutions. The vibrational peaks in the $\mathrm{C}-\mathrm{H}$ region were determined for $\mathrm{CH}_{2}$ symmetric stretch $\left(\mathrm{d}^{+}\right)$, $\mathrm{CH}_{3}$ symmetrical stretch $\left(\mathrm{r}^{+}\right)$and $\mathrm{CH}_{3}$ Fermi resonance $\left(\mathrm{r}_{\mathrm{FR}}\right)$ at $2,850,2,870$, and $2,935 \mathrm{~cm}^{-1}$, respectively. The $\mathrm{CH}$ peaks did not provide enough information on the bitumen surfaces. The vibration peak of water in the $\mathrm{OH}^{-}$region, instead, was found to be useful in providing better understanding of the interaction mechanism between water molecules and bitumen. The SFG results indicated that the bitumen surfaces are overall negatively charged and induce an ordered water structure near the bitumen surface with averaged $\mathrm{OH}^{-}$orientation pointing toward the bitumen. Additionally, hydroxide adsorption may increase the negative charges in the bitumen surface. Increasing the salt concentration, $\mathrm{NaCl}$ and $\mathrm{CaCl}_{2}$, significantly decreased the SFG intensities as well as the order of the interfacial water molecules. The SFG results showed also that $\mathrm{Ca}^{2+}$ is more effective than $\mathrm{Na}^{+}$in terms of the surface charge screening because of its higher charge.

Watanabe et al. [14] analyzed the interfacial molecular behavior of $n$-dodecane with added stearic acid $(0.05$ $\mathrm{wt} \%$ ) at a friction interface of fused quartz surfaces. Methylene stretching peak was observed at the interfaces for the dynamic condition only. The results indicated that the adsorption film of stearic acid was highly aligned and subsequently caused drastic changes in the interfacial structure of n-dodecane (gauche defects). The stearic acid adsorption film behaved as solid-like.

$\mathrm{C}-\mathrm{H}$ stretching mode frequencies of alkanes/air systems were thoroughly investigated from bulk measurements and at interface [15]. The ratio of $\mathrm{r}^{+} / \mathrm{d}^{+}$is commonly utilized as an indicator to measure the conformational order at the surfaces containing alkyl chains. The stretching modes, overall, are classified as either symmetric (SS) or antisymmetric stretching (AS). For example, if the two hydrogen atoms that are connected to carbon in $\mathrm{CH}_{2}$ group are moving in the same direction, then it is called symmetric stretching. In the antisymmetric stretching, the hydrogen atoms are moving in opposite directions.

Understanding the chemical interactions and structures at monolayer from SFG spectra consider very complex and challenging procedures $[16,17]$. Researchers from different industries analyzed the results in terms of gauche defects, $\mathrm{r}^{+} / \mathrm{d}^{+}$ratio, $\mathrm{OH}^{-}$band, hydrogen bonding, and $\mathrm{CO}^{-}$intensities. For perfect monolayers of alkyl chains at air/water interfaces, the peaks associated to the methyl group, $\mathrm{r}+, \mathrm{r}_{\mathrm{FR}}$, and $\mathrm{r}$ - are clearly identifiable. It is representing the situation where the monolayer possesses a perfect packing without any defects [9]. If the monolayer presents some gauche defects, then the related SFG spectrum of methylene groups $\left(\mathrm{d}^{+}\right)$should exist at the intensity chart. As the quantity of gauche defects increases, a decrease in the intensity from the $-\mathrm{CH}_{3}$ bands and an increase in the one coming from the $-\mathrm{CH}_{2}$ bands must be observed. Therefore, the ratio of the intensities $\left(\mathrm{r}^{+} / \mathrm{d}^{+}\right)$is commonly considered a semi-quantitative way in determining the number of gauche defects in the system (Table 1). The disturbance of the monolayer chemistry at interfaces increases the defects and so could make a favorable impacts on wettability.

Table 1. IR vibration assignments of all the possible peaks present in an IR-VIS SFG spectrum of an alkyl-chain region, *:

[9]

\begin{tabular}{|c|c|c|c|}
\hline \multirow{2}{*}{ Notation } & \multirow{2}{*}{$\begin{array}{c}\text { Description and } \\
\text { chemical } \\
\text { assignment }\end{array}$} & \multicolumn{2}{|c|}{ Frequencies $\mathbf{( c m}^{-1}$ ) } \\
\cline { 3 - 4 } & & $\begin{array}{c}\text { This } \\
\text { study }\end{array}$ & $\begin{array}{c}\text { From } \\
\text { literature* }\end{array}$ \\
\hline $\mathrm{d}^{+}$ & $\begin{array}{c}\text { Methylene } \\
\text { symmetric stretch }\end{array}$ & $\begin{array}{c}2,848 \\
\pm 4\end{array}$ & 2,850 \\
\hline $\mathrm{d}^{-}$ & $\begin{array}{c}\text { Methylene } \\
\text { asymmetric stretch }\end{array}$ & $\begin{array}{c}2,938 \\
\pm 6\end{array}$ & 2,915 \\
\hline $\mathrm{r}^{+}$ & $\begin{array}{c}\text { Methyl symmetric } \\
\text { stretch (CH3-SS) }\end{array}$ & $\begin{array}{c}2,876 \\
\pm 8\end{array}$ & 2,875 \\
\hline $\mathrm{OH}$ & Hydrogen bonds & \multicolumn{2}{|c|}{$3,000-3,500$} \\
\hline $\mathrm{OH}$ & Free hydroxide & \multicolumn{2}{|c}{3,700} \\
\hline
\end{tabular}

The broadband from 3,000 to $3,600 \mathrm{~cm}^{-1}$ is for the large distribution of $\mathrm{OH}$ hydrogen bonding stretching modes in which the oxygen is tetrahedral coordinated [18]. The energy region from 3,000 to $3,250 \mathrm{~cm}^{-1}$ is attributed to strong intermolecular in-phase hydrogen bonds of water molecules that give rise to a highly correlated hydrogen-bonding network.

The sharp free $\mathrm{OH}^{-}$peak (due to non-proton donor $\mathrm{OH}$ bonds) near $3,700 \mathrm{~cm}^{-1}$ has been considered the most easily interpreted part of the water spectrum [19]. It is assumed to arise from only the topmost layer of water molecules. Therefore, dissolved salt ions in water can certainly make interfacial concentration gradients and disturb the chemical structure at interfaces. As a result, a decrease in the $3700 \mathrm{~cm}^{-1}$ peak intensity upon the addition of salt is commonly attributed to the displacement or rearrangement of water molecules by ions and ion pairs near the surfaces. 
Table 2. Ionic composition of synthetic brine solutions at different salinities *. TDS: Total Dissolved Solids; ppm: part per millions

\begin{tabular}{|c|c|c|c|c|}
\hline \multirow{2}{*}{\multicolumn{2}{|c|}{$\begin{array}{c}\text { Ions } \\
\text { Cations/Anions }\end{array}$}} & \multicolumn{3}{|c|}{ Synthetic Brine Solutions } \\
\hline & & $\mathrm{NaCl}$ & Smart Water & High salinity water (HSW) \\
\hline $\mathrm{Na}^{+}$ & \multirow{3}{*}{ Cations } & 2,802 & 1,830 & 18,300 \\
\hline $\mathrm{Ca}^{2+}$ & & - & 65 & 650 \\
\hline $\mathrm{Mg}^{2+}$ & & - & 211 & 2,110 \\
\hline $\mathrm{SO}^{2-}$ & \multirow{3}{*}{ Anions } & - & 429 & 4,290 \\
\hline $\mathrm{Cl}^{-}$ & & 4,367 & 3,220 & 32,200 \\
\hline $\mathrm{HCO}_{3}{ }^{-}$ & & - & 12 & 120 \\
\hline \multicolumn{2}{|c|}{ TDS*,ppm } & 7,169 & 5,767 & 57,670 \\
\hline \multicolumn{2}{|c|}{ Ionic Strength } & 0.12 & 0.11 & 1.15 \\
\hline
\end{tabular}

\section{Experimental section}

Materials. The synthetic brine samples were prepared using the following ACS grades salts compounds: magnesium chloride hexahydrate, calcium chloride dihydrate, sodium sulfate anhydrous, sodium chloride and sodium hydrogen carbonate. Water purification system was utilized to purify and produce deionized water with a resistivity of $18.2 \mathrm{M} \Omega \cdot \mathrm{cm}$ at $25^{\circ} \mathrm{C}$. The salt solutions were dissolved in deionized water according to the chemical recipes in Table 2 and then filtered through $1 \mu \mathrm{m}$ filter paper. In addition to deionized water (DI water), three synthetic brines were tested including high salinity water (HSW), SmartWater and SmartWater enriched with sodium chloride $(\mathrm{NaCl})$. Deionized water is used as a reference sample and baseline for comparison with other solutions.

The used model oil is n-dodecane, $99 \%$; the impurities were carefully extracted through using column chromatography and aluminum oxide adsorbents material. The purification procedures were repeated four times to ensure the impurities were completely removed. The stearic acid (SA), 99\%, was thoroughly mixed with $\mathrm{n}$-dodecane to simulate the presence of carboxylic acid in crude oil. The acid ratio was approximately $0.0003 \mathrm{~g} / 1 \mathrm{~g}$ $\mathrm{n}$-dodecane, which mimic the acidity condition of oil in reservoirs.

The oil-in-water emulsion samples were prepared through sonicating $5 \mathrm{vol} \%$ of $n$-dodecane/SA in brine solutions for 3 minutes. Then, the emulsions were gently transferred to the SFG sample holder. In addition to oil/water interfaces, SFG tests were conducted for dodecane/air, dodecane/SA/air, and water/air interfaces. Apparatus and procedure. IR-visible sum frequency generation spectroscopy is based on a nonlinear optical technique which provides vibrational spectra of the surfaces and interfaces (Figure 1). In this study, picosecond laser pulses at a fixed visible wavelength and tunable IR wavelength are temporally and spatially overlapped at the interface of sample surfaces. The SFG spectrometer is based on picosecond pump laser and optical parametric generator (OPG) with difference frequency generation (DFG). Fundamental laser is split into several beams using the delivery unit. The outputs from the beam delivery are used for pumping OPG and DFG. One of the laser output beam, doubled in wavelength $(532 \mathrm{~nm})$, is directed to VIS channel of SFG spectrometer. IR wavelength of spectrometer is pumped by DFG output beam. The optical parameters, like beam diameter, pulse energy, delays between channels are aligned and matched.

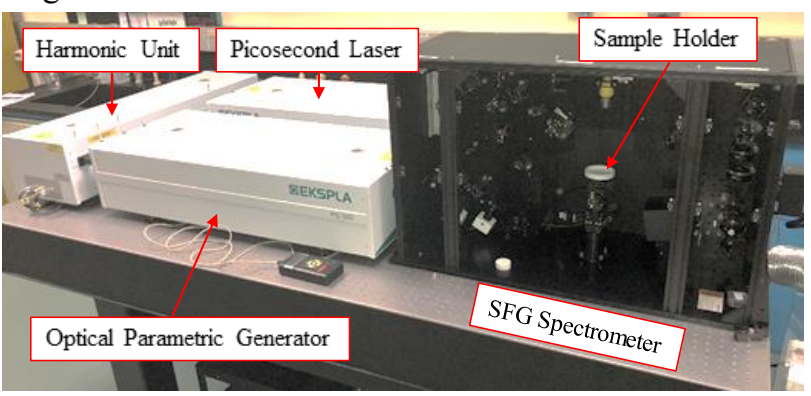

Fig. 1. Sum Frequency Generation Spectrometer Setup

SFG spectroscopy module provides all adjustable components accessible within outspread hands for sample positioning and coupling. One of IR polarization rotation are motorized and two are controlled manually. The SFG geometry is with co-propagating, non-collinear VIS and IR beams accessing the sample from top side and the SFG beam is being caught reflected from the sample surface. The incidence angle of VIS and IR beams is around 60 degrees, which guarantee best SFG efficiency. Detection system consists of monochromator with gated PMT based SF signal detector. System components are controlled from single dedicated software, which also provides automatic SFG spectra recording, dynamics monitoring, sample mapping, azimuthal scan and system parameters monitoring. The employed polarization in all of the SFG experiments is fixed at SSP.

\section{Result and discussion}

All vibrational sum frequency spectra in this study were acquired between 1,000 and $3,800 \mathrm{~cm}^{-1}$, a region in which $\mathrm{CH}_{2}, \mathrm{CH}_{3}, \mathrm{CO}$ and $\mathrm{OH}$ stretching band appears. The wide wavenumbers range was specifically selected for this studied oil systems, which composed of long alkyl chains 
$\left(\mathrm{C}_{12} \mathrm{H}_{26}\right)$ and acidic components. In addition, the carboxylic group of stearic acid has a higher tendency to align at the oil/water interfaces. The hydroxide molecules in water forms a strong hydrogen bonding as well as forming free $\mathrm{OH}$ ions.

The $\mathrm{pH}$ measurements were determined for all samples before and after the SFG experiments. As indicated in Table 3, the $\mathrm{pH}$ range was varied between 6.5 and 7.7 for $\mathrm{NaCl}$ brine and n-dodecane/SA/HSW emulsion sample accordingly. Minor changes in the $\mathrm{pH}$ observed after completing the tests and that could be due to the dissolved atmospheric $\mathrm{CO}_{2}$ effects. The n-dodecane droplet size distributions were determined using Zetasizer instrument which based on dynamic light scattering technology. The average droplet sizes of the ndodecane/SA in brines fluctuated between 280 and 880 nm for DI-water and HSW systems accordingly.

The dissolved ions effects on the interactions were evaluated first for the water/air interfaces for specific reasons. First, the salts mixtures might have some impurities which can adsorb at the interfaces and consequently alter the chemical interactions [20]. The second reason, for these tests, is to capture the ions behavior at different interfaces, air/water and oil/water. The SFG intensities of the tested brine solutions are compared along with the reference sample, DI-water (Figure 2). The results showed only three different peaks for hydrogen bonding, free $\mathrm{OH}$ and dissolved $\mathrm{CO}_{2}$. It confirmed that the used salts samples were pure and did not have any organic or inorganic contaminants. The ion interaction behaved differently in terms of hydrogen bonding network and free $\mathrm{OH}$ molecules and that will be discussed in more details in the next sections. The SFG is open system and, as such, atmospheric $\mathrm{CO}_{2}$ can easily dissolved in the brine samples. The impact of the $\mathrm{CO}_{2}$ on the chemical interactions was insignificant at $2,300 \mathrm{~cm}^{-1}$ and also confirmed from $\mathrm{pH}$ measurements pre and post each tests (Table 3 ).

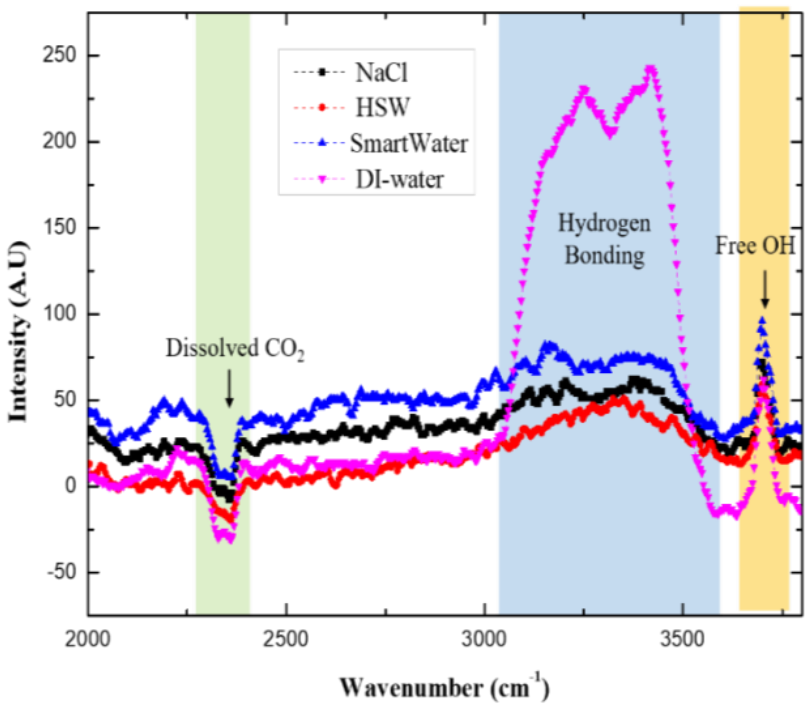

Fig. 2. SFG results of different brines at air/water interfaces.
Table 3. $\mathrm{pH}$ measurements of pure brines and emulsion samples before and after the SFG tests.

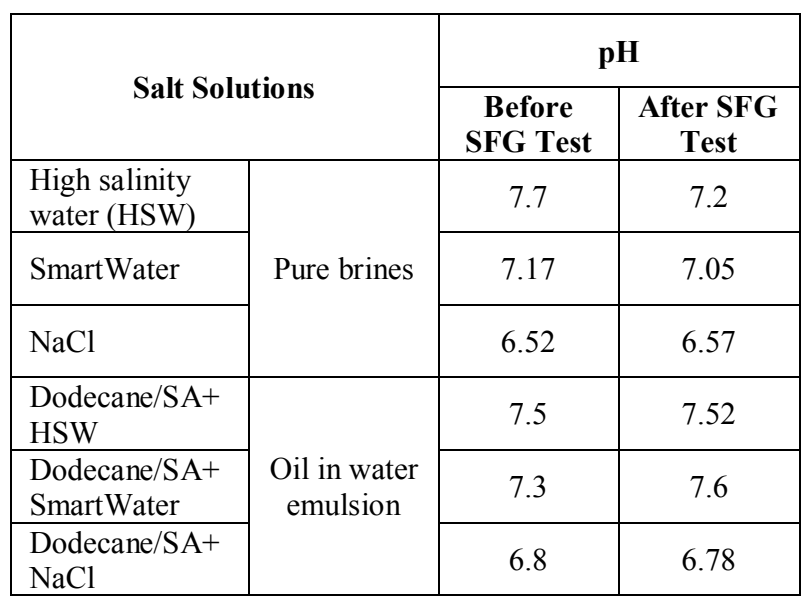

Carboxylic acid in oil. The carboxylic acid group $(\mathrm{C}=\mathrm{O})$ in the oil considered by several researchers as the key component in most of the fluid/fluid and fluid/rock interactions. Because of its deprotonation nature, more emphasis was directed to $\mathrm{C}=\mathrm{O}$ rather than $\mathrm{COO}^{-}$spectra. DI-water was solely used in this study to eliminate other ions effects especially the divalent ones as well as using this as a base-line. Figure 3 shows the SFG spectra of the dodecane/DI-water in presence and absence of stearic acid component. The SA evidently made a strong influence on the monolayer chemical structure in terms of $\mathrm{CH}_{3}$ and $\mathrm{CH}_{2}$ stretching bands. The $\mathrm{C}=\mathrm{O}$ components significantly enhanced the alkyl chain intensities of dodecane by more than 2 folds. Nonetheless, the hydroxide intensities in presence of carboxylic acid were partially enhanced. This indicates a strong hydrogen bonding is formed at the monolayer interface. Strong ionic binding is also formed between HSW and dodecane/SA systems which resulted in a slightly higher $\mathrm{C}=\mathrm{O}$ intensities in compare to SmartWater (Figure 4). As a result, the $\mathrm{C}=\mathrm{O}$ peaks were reduced as the ionic strength was decreased from 1.15 to 0.11 . The current findings are in agreement with a previous study evaluating the deprotonation of the $\mathrm{COOH}$ headgroup in palmitic acid [21]. The SFG instrument accuracy was also validated and tested with pure systems only (dodecane/air). The reported $\mathrm{r}+/ \mathrm{d}+$ ratio for dodecane in this study was 0.91 and showed a very close match with the published findings $(0.8 \pm 0.1)$ by Esenturk and Walker [15]. 


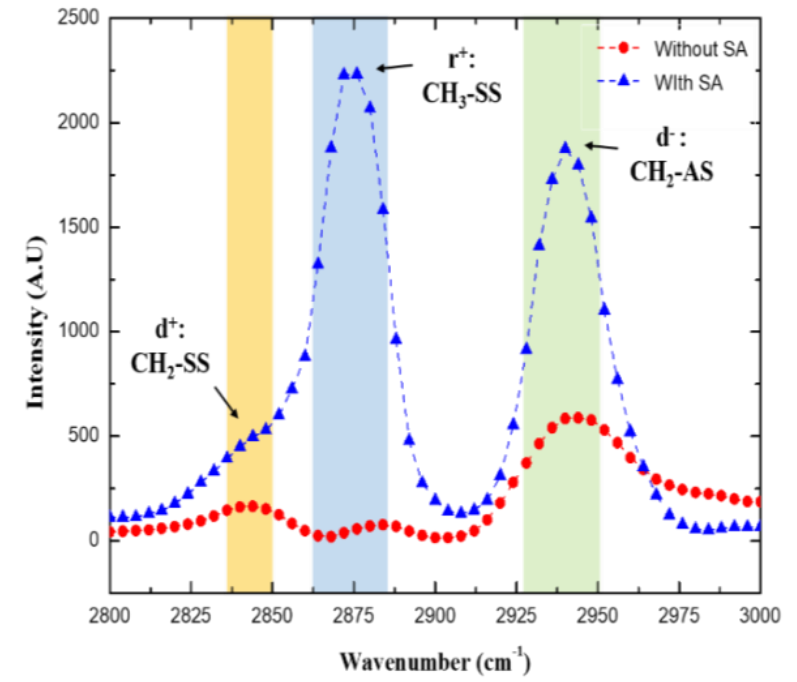

Fig. 3. The carboxylic acid effects on the SFG intensities of ndodecane/DI-water

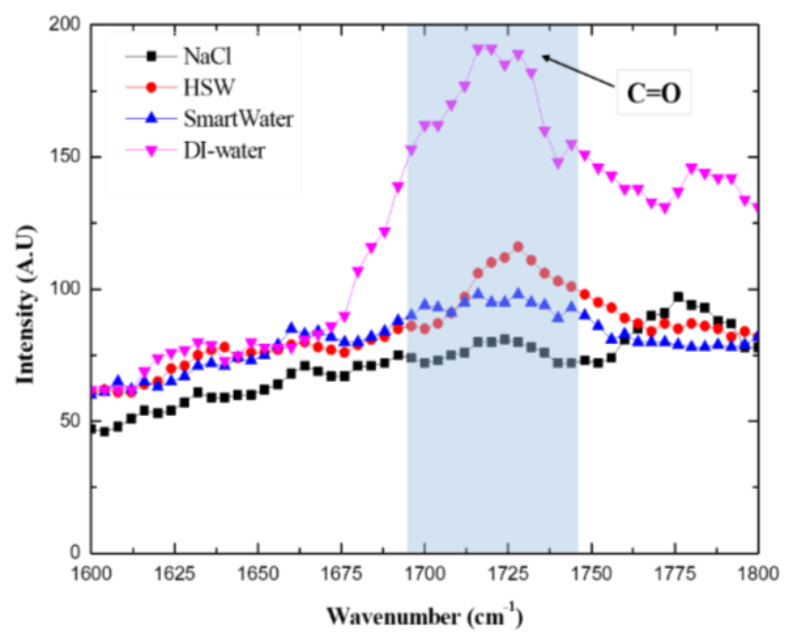

Fig. 4. The $\mathrm{C}=\mathrm{O}$ intensities of different brines at oil/water interfaces

Effect of ionic strength on the monolayer characteristic. The interactions of ions at oil/water interfaces were studied for HSW, SmartWater, SmartWater enriched in $\mathrm{NaCl}$ and DI-water. The ratio of stearic acid in the dodecane samples was kept unchanged for all emulsion tests. The conformational order of the components was investigated through calculating the $\mathrm{r}^{+} / \mathrm{d}^{+}$ratio (Table 4 ). The symmetric stretches of $\mathrm{r}^{+}, \mathrm{d}^{+}, \mathrm{d}^{-}$were obtained from the intensity plots at wavenumbers 2876, 2848 and 2938 $\mathrm{cm}^{-1}$ accordingly. SmartWater revealed the highest $\mathrm{r}^{+} / \mathrm{d}^{+}$ ratio when compared to the other solutions (Figures 4 and 5). The results indicated that the DI-water had the lowest ratio and subsequently resulted in small number of alkyl chain defects. The chemical interactions between water molecules and dodecane/SA produced a very well ordered monolayer [22]. The strong and narrow $r_{+}$band also implies a net perpendicular orientation of the methyl groups [15].

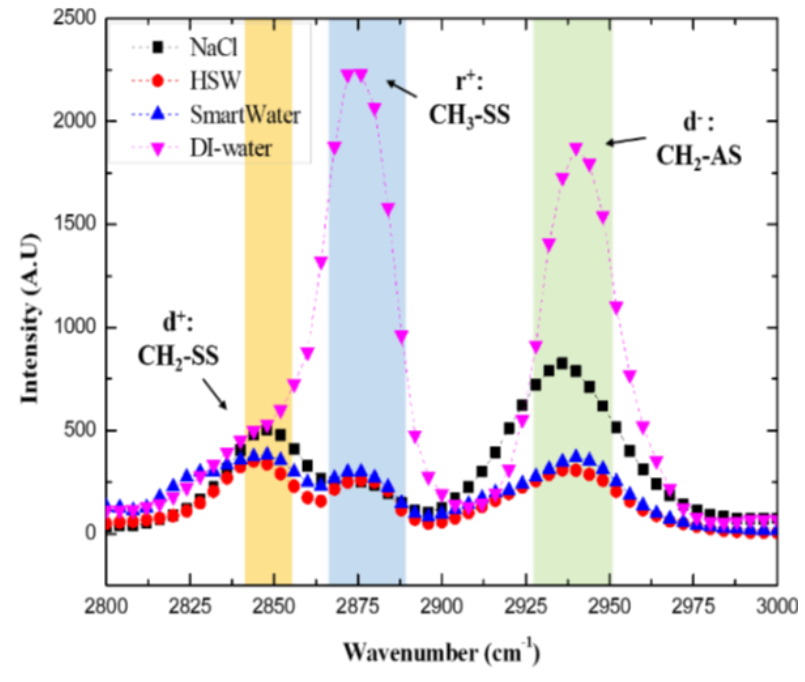

Fig. 5. The ionic strength effect on the SFG intensities of ndodecane/SA emulsions.

The methylene stretches intensities $\left(\mathrm{d}^{+} / \mathrm{d}^{-}\right)$shows the symmetric to antisymmetric $\mathrm{CH}_{2}$ ratio as a function of ionic strength (Figure 5). The HSW, for example, displayed the highest ratio in comparison to the other brines. This indicates that symmetrical $\mathrm{CH}_{2}$ stretches are more dominating. The $\mathrm{d}^{+} / \mathrm{d}^{-}$ratio significantly reduced once the ionic strength decreased from 1.15 to 0.11 (SmartWater). The orientation of the $\mathrm{CH}_{2}$ molecules in $\mathrm{n}$ dodecane has been clearly affected by the salinity and ionic contents. In the absence of divalent cations and anions, $\mathrm{NaCl}$ revealed more $\mathrm{CH}_{2}$ antisymmetric stretches than the symmetric ones. These interactions between dissolved ions and hydrocarbons at interfaces are not similar while using similar ionic strength solutions (SmartWater and $\mathrm{NaCl}$ ). Nonetheless, the reference DIwater sample produced the lowest $\mathrm{d}^{+} / \mathrm{d}^{-}$ratio with more antisymmetric stretches due to the hydrogen bonding effects.

Table 4. The intensities ratio of $\mathrm{r}+/ \mathrm{d}+$ and $\mathrm{d}+/ \mathrm{d}$ - for different $\mathrm{n}$-dodecane/SA emulsion samples dispersed in various brine solutions

\begin{tabular}{|c|c|c|c|c|}
\hline & $\begin{array}{c}\text { DI- } \\
\text { water }\end{array}$ & NaCl & HSW & SmartWater \\
\hline $\mathrm{r}^{+} / \mathrm{d}^{+}$ & 0.47 & 0.50 & 0.70 & 0.78 \\
\hline $\mathrm{d}^{+} / \mathrm{d}^{-}$ & 0.28 & 0.61 & 1.21 & 1.03 \\
\hline
\end{tabular}

Hydrogen bonding and free hydroxide ions. The hydrogen bonding at the interface increases with decreasing the ionic strength of the solution. As a result, the water molecules were well aligned in a more ordered structure for SmartWater solution than others. The DI-water sample confirmed such findings and formed a very broadband peak from 3,050 to $3,500 \mathrm{~cm}^{-1}$ (Figure 2). This indicates that the presence of salts in water neutralized the surface charge at the interfaces and destroyed the ordered structure of water molecules [13]. Nonetheless, the disturbance in the hydrogen-bonding network was observed to depend on the valency and effective ionic radius of the salt species in solution [23]. The divalent 
cations $\left(\mathrm{Ca}^{2+}, \mathrm{Mg}^{2+}\right)$ in water disrupted the hydrogen bonding structure around the carboxylate headgroup at oil/water interfaces [22]. In addition, both ions are known to have electrostatic interactions but $\mathrm{Ca}^{2+}$ showed slightly a stronger interaction with the carboxylate head group than $\mathrm{Mg}^{2+}$. In this study, the reduction in the hydrogen bonding network at the interfaces were more pronounced after using SmartWater and HSW. The hydrogen bonding network behaved similarly to other studies for sodium halide/air interfaces [24]. The spectra intensity decrease also provides an evidence of ion bindings to $\mathrm{COO}^{-}$and $\mathrm{CH}$ components, as the water molecules become less aligned and the headgroup becomes less ordered with respect to orientation [25]. Although, having similar ionic strength, SmartWater revealed less hydrogen bonding network at the interfaces than $\mathrm{NaCl}$. Therefore, mixing of different ions enhances the interactions at the monolayer in comparison to individual salt solutions. The contribution from water molecules to the ion interactions at monolayers believed to be inequivalent [19]. The current study confirmed some of the previous findings where the intensities decreased significantly while increasing $\mathrm{Na}$ and $\mathrm{Ca}$ concentrations accordingly. Sodium cations, for example, could interact with the dissociated acid groups and form -COONa salt [26].

The free hydroxide $\left(\mathrm{OH}^{-}\right)$ions were thoroughly investigated for both air/water and oil/water interfaces at approximately band of $3,700 \mathrm{~cm}^{-1}$ [27]. Figure 6 , shows that reducing the ionic strength of brines enhanced the intensity of free $\mathrm{OH}$ stretches at oil/water interfaces. Presence of cations and anions in HSW significantly reduced the intensity to 65 . The DI-water sample showed higher intensities than that of HSW. This implies that the dissolved salt ions could displace some water molecules at the interfaces, and thus reduces the number densities of free $\mathrm{OH}$ bonds. The concentration of free $\mathrm{OH}$ ions increased more for SmartWater, $\mathrm{NaCl}$, and DI-water than for HSW. On the contrary, more free $\mathrm{OH}$ molecules were observed at air/water interfaces in salt solutions (Figure 2 ). As a result, ions disrupted the water hydrogen bonding network through orienting water molecules in the solvation shells $[19,28]$. The negative interfacial potential at oil/water interfaces is believed to be induced by hydroxide ion adsorption [29]. The less abundant hydroxide ions in the system may prevent any further adsorption at the oil-water interface. The frequency of free $\mathrm{OH}$ band is commonly applied as an indicator of the presence of weak water-organic interactions present at the interfaces and relative strength of interactions [30]. The free $\mathrm{OH}$ frequency shifted from $3,708 \mathrm{~cm}^{-1}$ to $3,688 \mathrm{~cm}^{-1}$ in air/water and oil/water interfaces accordingly. Since only one type of model oil was tested in this study, no differences were observed on the frequency although of using different brine solutions.

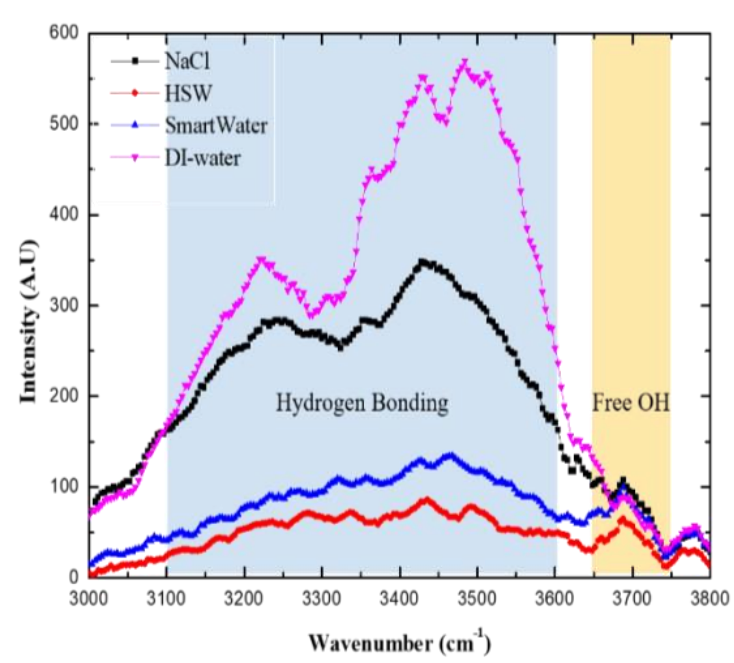

Fig. 6. Hydrogen bonding and free $\mathrm{OH}$ behaviors at ndodecane/SA/brine interfaces

\section{Conclusion}

The chemical structures of molecules at oil/water interfaces were characterized using SFG spectroscopy. Different brines recipes and model oil were used to determine the effects of individual and combined ions on the monolayer structures. In addition, stearic acid was also combined with hydrocarbons to mimic the acidity condition of fluids in the reservoir. Based on the SFG experiments performed at oil/water interfaces using different brines chemistries, the following major conclusions are drawn:

1. SmartWater significantly enhanced the $\mathrm{CH}_{3} / \mathrm{CH}_{2}$ stretching results, which increased the conformation order of the hydrocarbon chains. Such disturbance at the monolayer can make favorable impacts on rock wettability towards water-wet. The resulted change on wettability could potentially lead to additional oil recovery.

2. DI-water continuously displayed a strong hydrogen bonding network at both air and oil interfaces.

3. The carboxylic acid significantly enhanced the alkyl chain intensities of $n$-dodecane at the interfaces.

4. The hydroxide intensities in presence of carboxylic acid were partially improved. It indicates that a strong hydrogen bonds formed at the monolayer interfaces.

5. The interactions between dissolved ions and hydrocarbons at interfaces are not similar although of using similar ionic strength solutions (SmartWater and $\mathrm{NaCl}$ ).

6. The hydrogen bonding at the interfaces increased as decreasing the ionic strength of the solution.

7. Mixing different ions at low ionic strength enhanced the interactions at the monolayer in compare to individual salt solutions and HSW.

8. SmartWater revealed more free $\mathrm{OH}$ ions than HSW at the oil/water interfaces.

9. Results for DI-water SFG spectroscopy, displayed much higher intensities when compared to HSW. This is a direct indication that dissolved salt ions 
displaces some water molecules at the interfaces, resulting in reduced $\mathrm{OH}$ bonds densities, and its wetting condition.

\section{References}

1. Webb, K. J., Black, C. J. J., and Al-Ajeel, H. 2004. Low Salinity Oil Recovery - Log-Inject-Log. Paper SPE 89379 presented at the SPE/DOE Improved Oil Recovery Symposium, Tulsa, Oklahoma, USA, 1721 April.

2. Yousef, A.A., Liu, J.S., Blanchard, G.W., et al. 2012. SmartWater Flooding: Industry's First Field Test in Carbonate Reservoirs. Paper SPE 159526 presented at the SPE Annual Technical Conference and Exhibition, San Antonio, Texas, USA, 8-10 October.

3. Wolthers, M., Charlet, L., and Van Cappellen, P. 2008. The Surface Chemistry of Divalent Metal Carbonate Minerals; a Critical Assessment of Surface Charge and Potential Data Using the Charge Distribution Multi-site Ion Complexation Model. American Journal of Science 308(8): 905.

4. Strand, S., and Austad, T. 2008. Effect of Temperature on Enhanced Oil Recovery from Mixedwet Chalk Cores by Spontaneous Imbibition and Forced Displacement using Seawater. Energy \& Fuels 22(5): 3222.

5. Alotaibi, M.B., and Nasr-El-Din, H. A. 2011. Electrokinetics of Limestone Particles and Crude-Oil Droplets in Saline Solutions. SPE Reservoir Evaluation \& Engineering 14(5): 604-611.

6. Yousef, A.A., Al-Saleh, S.H., Al-Kaabi, A.O., et al. 2011. Laboratory Investigation of the Impact of Injection-Water Salinity and Ionic Content on Oil Recovery from Carbonate Reservoirs. SPE Reservoir Evaluation \& Engineering 14(5): 578.

7. Aguiar, H. B., "Vibrational Sum-Frequency Scattering Studies of Oil-in-Water Emulsions", Dissertation, École Polytechnique Fédérale de Lausanne, Swaziland, 2011.

8. Andrews, A. B., A. McClelland, O. Korkeila, A. Demidov, A. Krummel, O. C. Mullins, and Z. Chen, "Molecular Orientation of Asphaltenes and PAH Model Compounds in Langmuir-Blodgett Films using Sum Frequency Generation Spectroscopy", Langmuir, (2011) Vol. 10, 6049.

9. Andersen, A. "Surfactants Dynamics at Interfaces a Series of Second Harmonic Generation Experiments", Dissertation, University Potsdam, Germany, 2006.

10. Gragson, D. E., and G. L. Richmond, "Comparisons of the Structure of Water at Neat Oil/Water and Air/Water Interfaces as Determined by Vibrational Sum Frequency Generation", Langmuir, (1997) Vol. 13, 4804.

11. Hensel, J. K., A. P. Carpenter, R. K. Ciszewski, B. K. Schabes, C. T. Kittredge, F. G. Moore, and G. L. Richmond, "Molecular Characterization of Water and Surfactant AOT at Nanoemulsion Surfaces", PNAS, (2017) Vol. 114, 13351.
12. Laß, K., and G. Friedrichs, "Revealing Structural Properties of the Marine Nanolayer from Vibrational Sum Frequency Generation Spectra", J. Geophys. Res., (2011) Vol. 116, C08042.

13. $\mathrm{Hu}, \mathrm{D}$., and K. C. Chou "Surface Charge at the Bitumen/Water Interface Investigated by PhaseSensitive Sum Frequency Generation Vibrational Spectroscopy: Effects of pH, Ions, and Surfactants", Energy Fuel, (2015) 29, 7885-7888.

14. Watanabe, S., M. Nakano, K. Miyake, and S. Sasaki, "Analysis of the Interfacial Molecular Behavior of a Lubrication Film of n-dodecane Containing Stearic Acid under Lubricating Conditions by Sum Frequency Generation Spectroscopy", Langmuir, (2016) Vol. 32, 13649.

15. Esenturk, O., and R. A. Walker, "Surface Vibrational Structure at Alkane Liquid/Vapor Interfaces", J. Chem. Phys., (2006) Vol. 125, 174701.

16. Bain, C. D., P. B. Davies, T. H. Ong, R. N. Ward, and M. A. Brown, "Quantitative Analysis of Monolayer Composition by Sum-Frequency Vibrational Spectroscopy", Langmuir, (1991) Vol. 7, 1563.

17. Jang J. H., J. Jacob, G. Santos, T. R. Lee, and S. Baldelli, "Image Contrast in Sum Frequency Generation Microscopy Based on Monolayer Order and Coverage", J. Phys. Chem. C., (2013) Vol. 117, 15192.

18. Richmond, G. L., "Structure and Bonding of Molecules at Aqueous Surface", Annu. Rev. Phys. Chem., (2001) Vol. 52, 357.

19. Callahan, K. M., N. N. Casillas-Ituarte, M. Xu, M. Roseslová, H. C. Allen, and D. J. Tobias, “Effect of Magnesium Cation on the Interfacial Properties of Aqueous Salt Solutions", J. Phys. Chem. A, (2010) Vol. 114, 8359.

20. Fang, H., W. Wu, Y. Sang, S. Chen, X. Zhu, L. Zhang, Y. Niu, and W. Gan, "Evidence of the Adsorption of Hydroxide Ion at Hexadecane/Water Interface from Second Harmonic Generation Study", RSC Adv., (2015) Vol. 5, 23578.

21. Tang, C. Y., Z. Huang, and H. C. Allen, "Interfacial Water Structure and Effects of $\mathrm{Mg} 2+$ and $\mathrm{Ca} 2+$ Binding to the COOH Headgroup of a Palmitic Acid Monolayer Studied by Sum Frequency Spectroscopy", J. Phys. Chem. B, (2011) Vol. 115, 34.

22. Beaman, D. K., "Vibrational Sum-Frequency Spectroscopy Investigations of Carboxylic acid based Surfactants and Polymers at the Oil-Water Interface", Dissertation, University of Oregon, USA, 2010.

23. Covert, P. A., amd D. K. Hore, “ Geochemical Insight from Nonlinear Optical Studies of Mineral - Water Interfaces", Annu. Rev. Phys. Chem., (2016) Vol. 67, 233

24. Liu, D., G. Ma, L. M. Levering, and H. C. Allen, "Vibrational Spectroscopy of Aqueous Sodium Halide Solutions and Air-Liquid Interfaces: Observation of Increased Interfacial Depth", J. Phys. Chem. B., (2004) Vol. 108, 2252. 
25. Huang, Z., "Studies using Vibrational Sum Frequency Generation Spectroscopy: I. Salty Glycerol versus Salty Water Surface Organization: Bromide and Iodide Surface Propensities II. Influence of Salt Purity on $\mathrm{Na}^{+}$and Palmitic Acid Interactions" Dissertation, Ohio State University, USA, 2013.

26. $\mathrm{Hu}, \mathrm{D}$., "Studies of Charged Molecules at the Air/Water Interface by Sum Frequency Generation Vibrational Spectroscopy", Dissertation, the University of British Columbia, Canada, 2016.

27. Gan, W., W. Wu, F. Yang, D. Hu, H. Fang, Z. Lan, and Q. Yuan, "The Behavior of Hydroxide and Hydronium Ions at the Hexadecane-Water Interface Studied with Second Harmonic Generation and Zeta Potential Measurements", Soft Matter, (2017) Vol.13, 7962.

28. Shen, Y. R., and V. Ostroverkhov, "Sum-Frequency Vibrational Spectroscopy on Water Interfaces: Polar
Orientation of Water Molecules at Interfaces", Chem. Rev., (2006) Vol. 106, 1140.

29. Beattie, J., and A. M. Djerdjev, "The Pristine Oil/water Interface: Surfactant-free Hydroxidecharged Emulsions", Angew Chem Int Ed, (2004) 43, 27, 3568 .

30. Moore, F. G., and G. L. Richmond, "Integration or Segregation: How Do Molecules Behave at Oil/Water Interfaces?" Accounts of Chemical Research, (2008) Vol. 41, 739. 